\title{
The INK4-ARF (CDKN2A/B) Locus in Hematopoiesis and BCR-ABL-induced Leukemias
}

\author{
R.T. WILLIAMS* AND C.J. SHERR ${ }^{\dagger *}$ \\ *Departments of Oncology and ${ }^{\dagger}$ Genetics \& Tumor Cell Biology and ${ }^{\ddagger}$ Howard Hughes Medical \\ Institute, St. Jude Children's Research Hospital, Memphis, Tennessee 38105
}

\begin{abstract}
Senescence and apoptosis programs governed by the $\mathrm{Rb}$ and $\mathrm{p} 53$ signaling networks can counter tissue stem cell self-renewal. A master regulator of $\mathrm{Rb}$ and $\mathrm{p} 53$ is the INK4-ARF $(C D K N 2 A / B)$ locus that encodes two CDK inhibitors, $\mathrm{p} 16^{\mathrm{INK} 4 \mathrm{~A}}$ and $\mathrm{p} 15^{\mathrm{INK} 4 \mathrm{~B}}$, that maintain $\mathrm{Rb}$ in its active, hypophosphorylated form, and $\mathrm{p} 14^{\mathrm{ARF}}$ (p19 $9^{\mathrm{Arf}}$ in mice), that inhibits Mdm2 and activates $\mathrm{p} 53$. The $I N K 4-A R F$ genes are epigenetically silenced in hematopoietic stem cells but become poised to respond to oncogenic stress as blood cells differentiate. Inactivation of $I N K 4-A R F$ endows differentiated cells with an inappropriate self-renewal capacity, a defining feature of cancer cells. In BCR-ABL-induced (Philadelphia chromosome-positive $\left[\mathrm{Ph}^{+}\right]$) leukemias, INK4-ARF deletions frequently occur in clinically aggressive acute lymphoblastic leukemias $\left(\mathrm{Ph}^{+} \mathrm{ALLs}\right)$ but are not seen in more indolent $\mathrm{Ph}^{+}$ chronic myelogenous leukemia (CML) or in CML myeloid blast crisis. Mouse modeling of $\mathrm{Ph}^{+}$ALL reveals that $\mathrm{Arf}$ inactivation attenuates responsiveness to targeted BCR-ABL kinase inhibitors, enhances the maintenance of leukemia-initiating cells within the hematopoietic microenvironment, and facilitates the emergence of malignant clones that harbor drug-resistant BCR$\mathrm{ABL}$ kinase mutations. Thus, although BCR-ABL mutations typify drug resistance in both CML and $\mathrm{Ph}^{+} \mathrm{ALL}$, loss of INK4$A R F$ in $\mathrm{Ph}^{+} \mathrm{ALL}$ enhances disease aggressiveness and undermines the salutary effects of targeted therapy.
\end{abstract}

The $\mathrm{Ph}^{+}$, a balanced translocation between chromosomes 9 and 22, was the first identified cytogenetic anomaly linked to a specific form of human cancer (Nowell and Hungerford 1960; Rowley 1973). It is the founding genetic lesion of CML and a subset of $\mathrm{Ph}^{+}$ALLs. The $\mathrm{t}(9 ; 22)(\mathrm{q} 34 ; \mathrm{q} 11)$ translocation joins the $A B L 1$ oncogene on chromosome 9 to a breakpoint cluster region (BCR) on chromosome 22 to generate the BCR-ABL fusion oncoprotein, a constitutively active tyrosine kinase that initiates both diseases. In CML, the $\mathrm{p} 210^{\mathrm{BCR}-\mathrm{ABL}}$ isoform is initially expressed in hematopoietic stem cells (HSCs) and in their derivative myeloid and lymphoid progeny, whereas in $\mathrm{Ph}^{+}$ ALL, the synthesis of either of two alternative p185 or p210 isoforms is restricted to the B-cell lineage (Groffen et al. 1984; Chan et al. 1987; Clark et al. 1987).

Clinically, CML often presents as an indolent myeloproliferative disorder characterized by expansion within hematopoietic tissues of relatively mature myeloid cells that often spill over into the circulation. Such patients are said to be in chronic phase (CML-CP), but without effective therapy, they progress through an accelerated phase to lethal blast crisis (CML-BC) that resembles an acute leukemia and is distinguished by the rapid proliferation of primitive myeloid or lymphoid "blasts" in hematopoietic organs. De novo $\mathrm{Ph}^{+}$ALL resembles the lymphoid blast crisis of CML (CML-LBC) but without a clinically detectable chronic phase. Whole-genome single-nucleotide polymorphism (SNP) analysis indicates that CML-CP leukemic cells typically display no recurring gene amplifications or losses, consistent with the notion that BCR-ABL expression is necessary and perhaps sufficient to induce the early stages of disease (Mullighan et al. 2008b). In contrast, diagnostic blasts recovered from CML-LBC and $\mathrm{Ph}^{+} \mathrm{ALL}$ patients harbor several recurring genomic lesions, including frequent $I N K 4-A R F$ deletions (Mullighan et al. 2008a) that correlate with their decidedly poorer outcome, regardless of the therapeutic modalities used, as compared to CML-CP patients. $\mathrm{Ph}^{+}$ALL comprises a small fraction (5\%) of ALL cases in children, but it represents about one third of adult ALL, the largest genetically defined subgroup (Armstrong and Look 2005); tragically, the outcome for patients of both age groups is equally poor (Arico et al. 2000; Gleissner et al. 2002).

Targeted therapy with BCR-ABL kinase inhibitors has revolutionized the treatment of CML. Imatinib (Gleevec), the first-generation FDA-approved kinase inhibitor, successfully maintains virtually all CML-CP patients in remission as long as they continue drug therapy (Wong and Witte 2004; Druker et al. 2006). Nonetheless, most if not all drug-treated patients harbor persisting leukemic stem cells that rapidly expand and contribute to clinical relapse after drug discontinuation. Furthermore, a small percentage of patients $(5 \%$ in the first year and fewer thereafter) relapse despite continuous therapy, and the reappearance of leukemia is typically associated with development of drug-resistant mutations in the BCRABL kinase domain (KD) that impair drug binding (Shah et al. 2002). Second-generation BCR-ABL kinase inhibitors, including nilotinib (Tasigna) and dasatinib (Sprycel), were developed as more potent inhibitors that are capable of inhibiting many of the most frequent BCR$\mathrm{ABL}$ drug-resistant KD mutants, and these were FDA approved for use in imatinib-resistant or -intolerant CML and for $\mathrm{Ph}^{+}$ALL (Kantarjian et al. 2006; Talpaz et al. 2006; Hochhaus et al. 2007). Importantly, all three targeted drugs display no efficacy against one specific KD "gatekeeper mutation," T315I, that frequently emerges at clinical relapse, particularly when patients are treated with the broader spectrum, more potent, second-generation inhibitors. 
Although all three kinase inhibitors induce significant hematological and molecular responses in $\mathrm{Ph}^{+} \mathrm{ALL}$ patients, these are relatively short lived, and treated patients relapse despite continuous therapy within only 6 months of therapy initiation (Druker et al. 2001; Talpaz et al. 2006; Alvarado et al. 2007; de Labarthe et al. 2007); these patients frequently, but not invariably, harbor leukemic clones with drug-resistant KD mutations (Talpaz et al. 2006; Hochhaus et al. 2007; O'Hare et al. 2007). Similarly, the durable responses to kinase inhibition observed in CML-CP are not realized in CML-BC, suggesting that additional mutations "downstream" from the BCR-ABL kinase contribute to more aggressive disease and to the attenuated therapeutic response.

Here, we discuss the role that the CDKN2A-CDKN2B (INK4-ARF) tumor suppressors have in governing selfrenewal in normal and BCR-ABL-transformed hematopoietic cells. We outline how robust, clinically relevant mouse modeling of $\mathrm{Ph}^{+}$ALL (which combines BCRABL expression and Arf inactivation) provides unique opportunities for implementing treatment strategies and for interrogating drug resistance mechanisms that counter targeted therapeutic agents.

\section{THE INK4-ARF LOCUS AND CELLULAR SELF-RENEWAL}

Current evidence suggests that the INK4-ARF locus can exist in four distinct states: epigenetically silenced, poised for activation, overtly activated, and inactivated (Fig. 1). Epigenetic silencing of Ink4-Arf by Bmil-containing Polycomb complexes facilitates HSC self-renewal (Jacobs

\section{Four States of INK4-ARF}

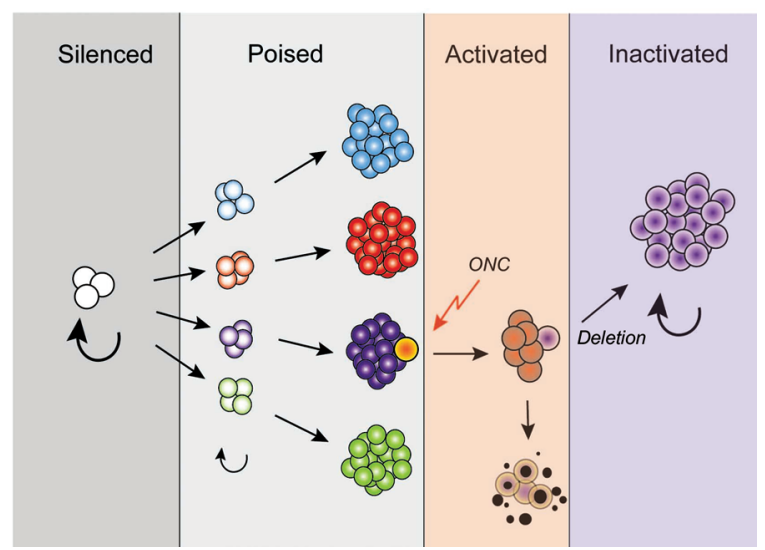

Figure 1. Four states of the INK4-ARF locus in hematopoietic cells. In HSCs that exhibit self-renewal capacity, the INK4-ARF locus is epigenetically silenced, whereas in progenitor cells and their progeny, the locus becomes poised to respond to various forms of stress, including sustained oncogenic signaling. Depicted is an oncogenic insult (ONC) that activates INK4-ARF, thereby eliminating the vast majority of cells through senescence or apoptosis. However, oncogene activation can also select for rare cells that have deleted the locus and acquire inappropriate self-renewal capacity. The latter cells have a greatly increased propensity to generate cancers. et al. 1999; Lessard and Sauvageau 2003; Park et al. 2003; Iwama et al. 2004; Akala et al. 2008). Although Bmil null mice are born with normal blood elements, they become aplastic within the first 2 months of life due to the loss of functional HSCs. The fact that this phenotype is manifested only after birth stems from the fact that the integrity of Bmil-containing complexes is not required for HSCs within the fetal liver. However, during the first few weeks after birth, hematopoiesis becomes dependent on "definitive" HSCs that reside within the bone marrow where the requirement for Bmil becomes apparent. Although Bmilcontaining Polycomb complexes can regulate many genes, the maintenance of definitive adult HSCs depends strongly on Ink4a and Arf, because disruption of these genes significantly rescues blood cell formation in Bmil null animals. Interestingly, mice that lack Ink4a, Ink $4 b$, and $A r f$ are even more highly prone to tumor development than mice lacking Ink $4 a$ and Arf, implicating an additional "back-up" role for Ink $4 b$ in tumor suppression (Krimpenfort et al. 2007) and raising the possibility that Bmil null mice lacking the entire Ink4-Arf gene cluster might fare even better. Recent findings suggest that HSCs lacking Ink4a-Arf and p53 lose their self-renewal potential and instead more rapidly generate transient amplifying cells that, although able to contribute to all blood cell lineages, exhibit diminished long-term repopulating activity after transplantation into irradiated recipients (Akala et al. 2008). Together, these findings point to the possibility that the Ink4-Arf locus acts as a gatekeeper in helping to establish the equilibrium between HSC self-renewal and the early differentiation steps that lead to lineage commitment.

As HSCs produce transiently amplifying progeny that undergo differentiation to form the various blood cell lineages, the Ink4-Arf locus is epigenetically remodeled and becomes "poised" to respond to abnormally increased and sustained thresholds of hyperproliferative signals (Fig. 1). Although the products of the locus are not detectably expressed under most normal circumstances, constitutively activated oncogenes can induce Arf expression and thereby trigger a p53-dependent transcriptional program that can eliminate oncogene-stressed cells through their senescence or apoptosis, the latter response being the more typical outcome for blood cells. Early Bcell progenitors are particularly sensitive to the oncogenic BCR-ABL kinase that efficiently induces an "activated" state of Arf expression. Although the accompanying p53dependent apoptosis eliminates the vast majority of incipient leukemic cells, rare BCR-ABL-positive cells that sustain Ink4-Arf deletion can survive and acquire an abnormal self-renewing capacity that promotes leukemogenesis. Therefore, inactivation of the Ink4-Arf locus in cancer implies that the checkpoint had been activated at some earlier stage of tumor evolution (Fig. 1).

\section{LINEAGE SPECIFICITY AND SELF-RENEWAL IN BCR-ABL-INDUCED LEUKEMIAS}

CML-CP conforms to the cancer stem cell model in that the initiating BCR-ABL translocation develops in HSCs that can either self-renew or differentiate to more abundant mature progeny that are themselves nontumorigenic 
(Clarke et al. 2006). We therefore anticipated that in $\mathrm{Ph}^{+}$ HSCs, like their nontransformed counterparts, epigenetic silencing would prevent INK4-ARF activation and thereby bypass any selection pressure for the subsequent deletion of the locus. However, because BCR-ABL-positive HSCs can generate more mature lymphoid and myeloid cells, these differentiated progeny should lose their capacity to silence INK4-ARF. Thus, in the accelerated phase of disease that leads to CML-LBC, we expected that the INK4$A R F$ locus would first be activated and then deleted, ultimately facilitating the acquisition of abnormal selfrenewal capacity in lymphoid blasts that sustain the aggressive phase of the disease. The transition from CML$\mathrm{CP}$ to CML-LBC is associated with a dramatic decline in patient survival despite the advent of therapies targeting BCR-ABL, implying that INK4A-ARF deletion might again be a deciding factor. Conceptually, de novo $\mathrm{Ph}^{+}$ ALL is like CML-LBC without a preceding chronic phase, consistent with the observation that the founding BCR$\mathrm{ABL}$ translocation is restricted to lymphoid progenitors in this disease (Castor et al. 2005).

Recently, the frequencies of INK4-ARF deletions in $\mathrm{Ph}^{+}$ALL and CML-LBC have been determined in an extended cohort of pediatric and adult patients by use of high-density microarray platforms that detect SNP arrays and by quantitative genomic polymerase chain reaction (PCR) analysis (Mullighan et al. 2008a,b). Whereas the INK4-ARF locus was intact in cells from CML-CP patients and those in myeloid blast crisis (CML-MBC), approximately two thirds of cases with $\mathrm{Ph}^{+} \mathrm{ALL}$ or CMLLBC exhibited monoallelic or biallelic INK4-ARF deletions at the time of diagnosis (Table 1). In addition, these same patients also sustained frequent deletions of genes encoding two transcriptional regulators of the B-cell differentiation pathway - specifically, IKFZ1 (Ikaros) and $P A X 5$. Inactivation of these genes, frequently monoallelic, is expected to retard B-cell maturation and to expand the pool of $\mathrm{Ph}^{+}$-committed B-lymphoid cells that are susceptible to further mutational events, such as INK4-ARF loss. Aberrant recombination-activating gene (RAG)-mediated recombination events appear to underlie IKFZ1 deletions and seem also to have a role in genomic deletions of the INK4-ARF locus in $\mathrm{Ph}^{+} \mathrm{ALL}$ as well (Mullighan et al. 2008b), as has previously been described in T-cell ALL (Kohno and Yokota 2006). (In contrast, INK4-ARF deletions in many other forms of can-

Table 1. Frequency of deletions in ALL

\begin{tabular}{lcccc}
\hline & & \multicolumn{3}{c}{ Gene deletion frequency (\%) } \\
\cline { 3 - 5 } Subcategory & No. cases & IKAROS & PAX5 & CDKN2A/B \\
\hline $\mathrm{Ph}^{+} \mathrm{B}-A L L^{\mathrm{a}}$ & 43 & 84 & 51 & 54 \\
Non-Ph $^{+} \mathrm{B}-A L L$ & 211 & 11 & 30 & 32 \\
T-ALL & 50 & 4 & 10 & 72
\end{tabular}

${ }^{a}$ No significant differences in gene deletion frequencies were observed between 21 pediatric and 22 adult cases subjected to analysis. Study of the $C D K N 2 A$ / $B$ gene cluster in 41 of these cases by quantitative PCR using primers directed to each of the $I N K 4 A, A R F$, and $I N K 4 B$ exons indicated an overall deletion frequency of $64 \%$. cer seem to occur through RAG-independent recombination across regions of microhomology). The occurrence of RAG-dependent deletions in $\mathrm{Ph}^{+}$lymphoid leukemias is likely to provide one explanation for the increased frequencies of INK4-ARF deletions in various forms of ALL versus their relative paucity in CML-MBC.

What molecular lesions contribute to acquisition of self-renewal in CML-MBC if the INK4-ARF locus is intact? The p53 tumor suppressor itself is mutated in a significant fraction of these patients (Calabretta and Perrotti 2004), reinforcing the idea that the p53-dependent tumor suppressor pathway is frequently targeted in blastic transformation of CML, but that the mechanisms differ between the lymphoid (INK4-ARF deletions) and myeloid ( $p 53$ mutations) lineages. Additional lineagespecific mechanisms may also contribute to the selfrenewal of myeloid blasts. For example, aberrant $\beta$-catenin signaling confers self-renewal to lineage-committed granulocyte-macrophage progenitors in CMLMBC (Jamieson et al. 2004) but is dispensable for BCR-ABL-induced ALL (Zhao et al. 2007).

\section{MODELING $\mathrm{PH}^{+}$ALL IN THE MOUSE}

We developed a highly efficient murine $\mathrm{Ph}^{+} \mathrm{ALL}$ model system that entails the rapid ex vivo generation of primary, bone-marrow-derived populations of murine $\mathrm{Arf}^{-/-}$pre-B cells that express $\mathrm{p} 185^{\mathrm{BCR}-\mathrm{ABL}}$. Introduction of these cells into healthy immunocompetent, syngeneic recipient host animals (hereafter "recipients") generates a fulminant ALL that quickly kills the mice. In direct contrast to the retarded leukemogenic potential of $\mathrm{p} 185^{+} ; \mathrm{Arf}^{+/+}$cells in healthy animals, as few as $20 \mathrm{p} 185^{+} ; A r f^{-/}$cells are capable of producing a disseminated pre-B-cell ALL in recipients in less than 4 weeks (Williams et al. 2006, 2007). Abundant leukemic cells "marked" with green fluorescent protein (GFP) (expressed in tandem with BCR-ABL) can be recovered from all hematopoietic tissues of moribund animals and can be readily phenotyped, quantified, cultured in vitro, and efficiently transplanted serially and at the same limiting dilution into healthy secondary and tertiary recipients. Molecular assessments of immunoglobulin heavy $(\mathrm{IgH})$ chain gene rearrangements and vector insertion sites, and measures of leukemogenic potential of multiple, independent single-cell-derived clones, revealed that virtually every $\mathrm{p} 185^{+} ; \mathrm{Arf}^{-/}$donor pre-B cell has leukemia-initiating cell (LIC) capacity. Thus, BCR-ABL expression combined with $A r f$ inactivation is sufficient to guarantee ALL induction.

Although a variety of immunophenotypic markers have been identified that are associated with rare or infrequent "cancer stem cell" subpopulations in myeloid leukemias (Clarke et al. 2006), the Arf null status of $\mathrm{p} 185^{+}$pre-B cells represents a molecular determinant that confers at least a 4-log increase in their leukemogenic potential (Williams et al. 2007). The p185 ${ }^{\mathrm{BCR}-\mathrm{ABL}}$ kinase confers growth factor (cytokine) independence to cells within the B-cell lineage; in contrast, Arf inactivation impairs BCR$\mathrm{ABL}$-induced apoptosis and dramatically facilitates the acquisition of limitless replicative potential by committed pre-B cells. The latency and phenotype of $\mathrm{p} 185^{+} ; \mathrm{Arf}^{-{ }_{-}}$- 
induced ALL are mimicked in $\mathrm{p} 185^{+}$cells that lack $p 53$, suggesting that most, if not all, of Arf's tumor-suppressive function is mediated via the $A r f-M d m 2-p 53$ axis.

One key aspect of this $\mathrm{Ph}^{+} \mathrm{ALL}$ model is that the donor animals, from which transformed $\mathrm{p} 185^{+}$pre-B cells are derived, and the recipient mice are of the same genetic background, thereby preventing immune-mediated rejection of donor LICs. The system was developed with C57BL/6 mice, a strain that is ordinarily relatively resistant to BCR-ABL transformation. Although most experimental models of leukemia involve engraftment of modified donor bone marrow into lethally irradiated recipients, our model more closely recapitulates events in patients, in which somatic mutations initiate tumor development in the context of an otherwise healthy, immune competent host.

Implementation of luminescent imaging approaches in this $\mathrm{Ph}^{+} \mathrm{ALL}$ model system has now permitted spatial and temporal assessments of leukemic cell engraftment, expansion, and dissemination in vivo. Whereas previous studies relied on a murine stem cell virus (MSCV)-based p185-IRES (internal ribosome entry site)-GFP retroviral vector that encoded both p185 and a GFP marker gene in tandem, a luciferase reporter gene has now been substituted for GFP, thereby creating an analogous p185-IRESLuc vector. Importantly, $\mathrm{p} 185^{+} ; \mathrm{Arf}^{-/} ; \mathrm{GFP}^{+}$donor cells and $\mathrm{p} 185^{+} ; \mathrm{Arf}^{-/} ; \mathrm{Luc}^{+}$cells produce equally aggressive disseminated pre-B-cell lymphoblastic leukemias on a per cell basis after inoculation into healthy recipients (Fig. 2). In the representative study illustrated here, 200,000 $\mathrm{p} 185^{+} ; \mathrm{Arf}^{-1-} ; \mathrm{Luc}^{+}$cells were injected intravenously (by tail vein) into a cohort of healthy recipient mice on day 0 , and mice were serially imaged every 3-4 days until their clinical deterioration necessitated their sacrifice at day 13 . One noninjected animal was included as a negative imaging control, and all of the luminescent images presented in Figure 2 (top) were captured and analyzed under identical conditions.

Several important observations stem from these studies. First, the luminescent signal (i.e., disease) was barely detectable 3 days after inoculation of LICs, whereas by day 7 , disseminated signals were appreciable in the limbs, sternum (bone marrow), and abdomen overlying the spleen. By days 10 and 13, further leukemic dissemination was observed as manifested by intense signals in the tail (likely reflecting circulating leukemic cells in the vasculature) and in the head region (reflecting leukemic infiltration into the meninges and into the calvarial bone marrow). Second, quantification of whole-animal luminescence revealed that there was significant consistency of signal among cohorts of animals analyzed at the same intervals and that there was an average log increase in signal intensity every 3 days (Fig. 2, bottom). This result is consistent with prior observations that leukemia onset is delayed by about 3 days for each $\log$ reduction in numbers of injected donor leukemogenic cells (Williams et al. 2007). Third, there is an approximately $3-\log$ dynamic range of signal between barely detectable disease (i.e., just above background) at day 3 and that emanating from moribund recipient animals at day 13 (Fig. 2, bottom). These features now provide further opportunities to understand the biology of the disease in real time, test the efficacy of
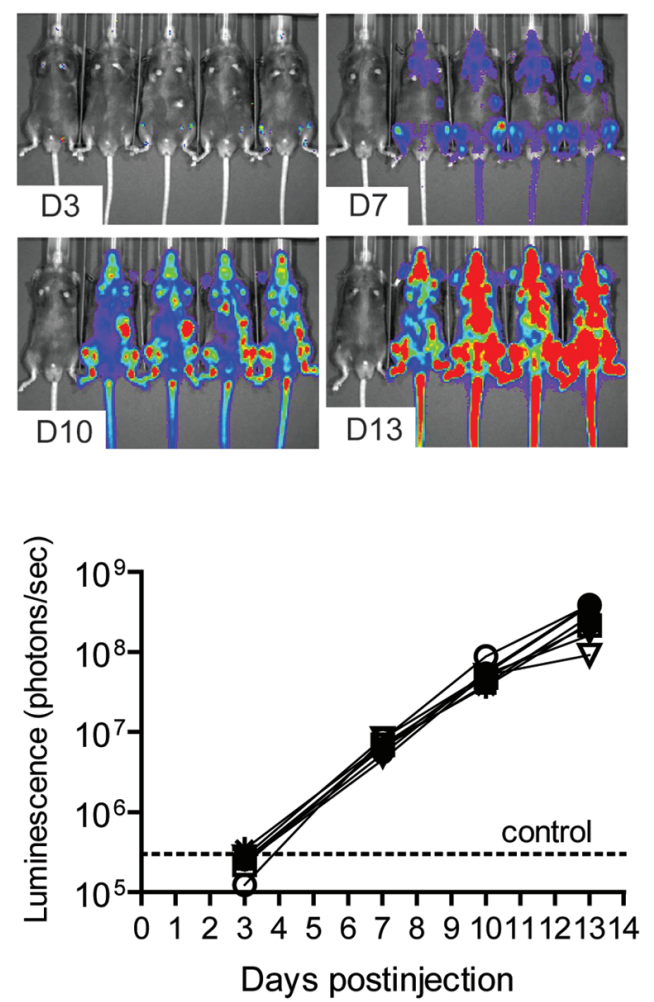

Figure 2. In vivo luminescent imaging of murine $\mathrm{Ph}^{+}$ALL. (Top) Serial luminescent images were captured every 3-4 days after intravenous injection of $200,000 \mathrm{p} 185^{+} ; \mathrm{Arf}^{-1}$ luciferaseexpressing pre-B cells. (Bottom) Whole-body luminescent activity was quantified in these mice at the indicated times (days) thereafter. Each symbol and connecting line represents tumor progression in an individual animal.

therapeutic agents, develop novel treatment strategies, and interrogate mechanisms of antileukemic drug resistance.

\section{RESISTANCE TO TARGETED THERAPY IN $\mathrm{PH}^{+}$ALL}

In contrast to the success of BCR-ABL-targeted therapeutics in maintaining CML-CP patients in durable remission, patients with $\mathrm{Ph}^{+}$ALL typically experience significant early responses to single-agent kinase inhibition but then relapse, often with drug-resistant BCR-ABL KD mutations. Maximal intensity imatinib therapy (100 $\mathrm{mg} / \mathrm{kg}$ twice per day by oral gavage) had only modest activity in our $\mathrm{Ph}^{+}$ALL mouse model (Williams et al. 2006), despite significant efficacy of the identical treatment regimen in murine CML models. Furthermore, these studies revealed that nontumor-cell-autonomous (cellextrinsic) imatinib resistance, mediated in part through cytokine signaling within the hematopoietic microenvironment, contributed to therapeutic resistance in vivo (Williams et al. 2007).

We therefore initiated therapeutic trials with dasatinib, reasoning that its significantly enhanced potency relative to imatinib, coupled with its ability to inhibit the Src family of nonreceptor tyrosine kinases, would lead to an enhanced therapeutic response in vivo (Shah et al. 
2004). Dasatinib is about 300 -fold more potent than imatinib in in vitro measures of growth inhibition of p $185^{+} ; \mathrm{Arf}^{-/-}$cells. In contrast to earlier trials in which imatinib therapy was initiated 3 days after inoculation of p185 ${ }^{+} ;$Arf $^{-/} ; \mathrm{GFP}^{+}$cells, dasatinib treatment $(10 \mathrm{mg} / \mathrm{kg}$ twice per day by gavage) was commenced 10 days after introduction of $200,000 \mathrm{p} 185^{+} ; \mathrm{Arf}^{-1-}$ Luc $^{+}$cells. These day-10 recipients were estimated to have a 100 -fold increase in leukemic burden compared to day-3 mice (see Fig. 2). They demonstrated clinical signs of leukemic cell expansion (lethargy, ruffled coat, reduced mobility) and typically had infiltration of their bone marrow compartment with $20-40 \%$ leukemic cells (a level of disease that would confer a diagnosis of ALL in a human patient). Luminescent imaging confirmed that cohorts of recipient animals had comparable disease burdens when therapy was initiated and allowed us to prospectively monitor the therapeutic response (Fig. 3, top). As expected, all vehicle-treated control mice succumbed to their leukemia within 3-4 more days (not shown). Remarkably, dasatinib therapy induced a dramatic reduction in disease burden within 1 week, and after 2 weeks of therapy, there was a 30-100-fold reduction in whole-animal luminescent signals (Fig. 3, bottom). Despite continuous twice-daily dasatinib therapy, however, all mice had persistent levels of measurable disease during the 10-week treatment window, and as therapy continued, virtually all animals relapsed with overt clinical signs of leukemia that closely correlated with dramatic increases in whole-body luminescent signals (Fig. 3, bottom). At relapse, many animals demonstrated foci of enhanced luminescent signals over their head and neck region, and often, these mice had clinical signs of central nervous system disease, including a bulging skull, irritability, and erratic behavior.

The significant initial response of murine $\mathrm{Ph}^{+} \mathrm{ALL}$ to dasatinib therapy followed by therapeutic failure despite continuous therapy is reminiscent of the clinical experience with dasatinib and nilotinib in human $\mathrm{Ph}^{+}$ALL (Kantarjian et al. 2006; Talpaz et al. 2006; Hochhaus et al. 2007). Molecular analysis of these dasatinib-resistant murine $\mathrm{Ph}^{+}$leukemias has now revealed that a significant number of them individually harbor clones with BCRABL KD mutations that have been previously identified in human clinical trials. Indeed, the most frequently encountered KD mutation (T315I) in mice that relapsed on dasatinib dramatically impairs kinase inhibition by all three FDA-approved BCR-ABL inhibitors (imatinib, nilotinib, and dasatinib) and represents one of the key resistance determinants in treated $\mathrm{Ph}^{+}$ALL patients. The acquisition of dasatinib-resistant KD mutants further reinforces the notion that the combination of BCR-ABL expression and Arf inactivation faithfully models the biology, genetics, and therapeutic responses of human $\mathrm{Ph}^{+}$ ALL and will provide unique opportunities to further interrogate the genesis of drug resistance in vivo.

Despite the considerable dasatinib-induced "debulking" of leukemic burden, there are tissue compartments that harbor functionally dasatinib-resistant cell populations in treated mice. What are the factors that contribute to the persistence of disease and facilitate the emergence
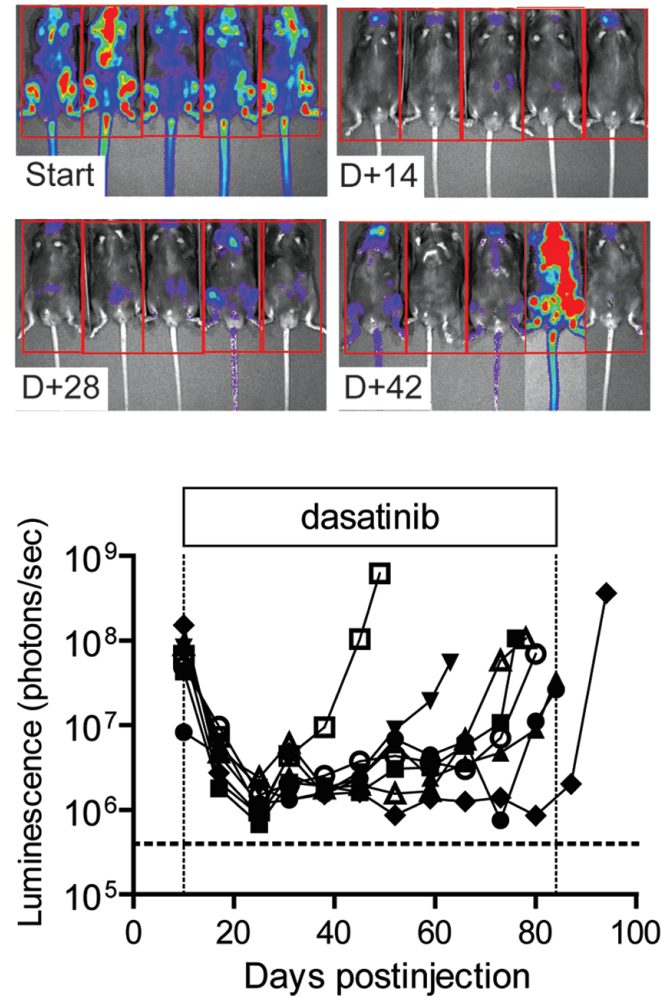

Figure 3. Dasatinib response and relapse of murine $\mathrm{Ph}^{+}$ALL. (Top) Serial luminescent images were captured at the start of therapy (Start) 10 days after injection of $200,000 \mathrm{p} 185^{+} ; \mathrm{Arf}^{-/}$ luciferase-expressing pre-B cells. Total body luminescence was quantified at the indicated days (D) thereafter as animals were maintained on continuous, twice-daily dasatinib therapy. An animal with elevated signal (abundant disease) at D+42 underwent relapse. (Bottom) Whole-body luminescent activity was quantified from these mice at the start of therapy and at weekly intervals during the course of dasatinib treatment and is plotted against time (days) after injection of donor cells. Twice-daily dasatinib therapy was continued for 10 weeks. Each symbol and connecting line represents an individual animal, all of which ultimately relapsed.

of drug-resistant mutants in the face of continuous therapy? A trivial explanation would be that mice are receiving suboptimal doses of dasatinib, but our experience suggests that the current dosing schedule is maximally intensive in animals that harbor significant disease burdens at the time of initiation of therapy. Alternatively, local drug concentrations in certain tissue microenvironments might fluctuate around cytostatic levels, but not cytotoxic levels, particularly when leukemic cells are protected by host factors produced through their interactions with stromal cells and extracellular matrix components. Moreover, the levels of dasatinib achieved in particular organ compartments might be suboptimal, a phenomenon that likely contributes to relapse within the central nervous system.

The unifying hypothesis is that in the context of BCRABL-driven lymphoid leukemias, Arf inactivation enhances the biological fitness of LICs, thereby promoting more efficient dissemination of leukemic cells, diminishing the efficacy of targeted therapy, and facilitating the 
emergence of cell-intrinsic drug resistance, most frequently manifested by BCR-ABL KD mutations. We reason that persistent BCR-ABL kinase activity initially selects for INK4-ARF deletions in vivo. Subsequently, nontumor-cell-autonomous drug resistance mechanisms operate to sustain a residual pool of viable $\mathrm{p} 185^{+} ; \operatorname{Arf}$ null leukemic cells during therapy. Persistent drug exposure then selects for the acquisition of drug-resistant BCR$\mathrm{ABL} \mathrm{KD}$ mutations in some cells that further expand. If INK4-ARF inactivation similarly facilitates acquisition of drug-resistant BCR-ABL mutations in humans, the third of $\mathrm{Ph}^{+}$ALL patients that retain the gene cluster at diagnosis might respond better than the majority to targeted therapy. Conversely, $\mathrm{Ph}^{+}$ALL patients that have already sustained INK4-ARF loss may need to be treated with the most potent kinase inhibitors together with conventional therapeutic agents or, ideally, with drugs that target the interaction of LICs with the host hematopoietic microenvironment.

\section{CONCLUSIONS}

In the hematopoietic system, the INK4-ARF locus functions as a master regulator of $\mathrm{Rb}$ and $\mathrm{p} 53$ function to prevent inappropriate progenitor cell self-renewal and to eliminate incipient cancer cells driven by sustained oncogenic signaling. Analysis of two distinct $\mathrm{Ph}^{+}$ leukemias provides clear evidence that whereas the $I N K 4-A R F$ locus is intact (and likely silenced) in CML, a disease that is very responsive to targeted therapies, frequent deletion of INK4-ARF occurs in BCRABL-dependent lymphoid leukemias (CML-LBC and $\left.\mathrm{Ph}^{+} \mathrm{ALL}\right)$ and correlates with transient responses to therapy and poor survival. Our highly efficient murine $\mathrm{Ph}^{+}$ALL model has been further refined and has several desirable features that facilitate biological and therapeutic investigations. First, the leukemic phenotype is very robust and mimics the genetics and biology of human ALL, including frequent dissemination of leukemic cells to the central nervous system. Second, fixed numbers of tagged, homogeneous, and genetically defined $\left(\mathrm{p} 185^{+} ; \mathrm{Arf}^{--}\right.$) donor cells, when engrafted into the hematopoietic system of an otherwise healthy syngeneic recipient, imitate the effects of the somatic mutation that initiates $\mathrm{Ph}^{+} \mathrm{ALL}$ in human patients. Third, disease burden can be monitored and quantified in real time before and in response to therapy, permitting the tracking of individual treatment responses and relapse. Fourth, in response to different targeted treatment protocols, we can now characterize the in vivo emergence and spectrum of drug-resistant BCR-ABL mutations. Collectively, these features underscore the value of modeling human cancer through innovative applications of mouse genetic systems and emphasize the utility of controlled preclinical "trials" for efficiently implementing and evaluating new therapeutic strategies.

\section{ACKNOWLEDGMENTS}

We thank members of the Sherr/Roussel and Williams laboratories for their contributions throughout the course of these studies. This work was supported in part by Cancer Center Core grant CA21765 and by ALSAC of St. Jude Children's Research Hospital. C.J.S. is an Investigator of the Howard Hughes Medical Institute.

\section{REFERENCES}

Akala, O.O., Park, I.-K., Qian, D., Pihalja, M., Becker, M.W., and Clarke, M.F. 2008. Long-term haematopoietic reconstitution by $\operatorname{Trp} 53^{-/}, \mathrm{p} 16^{\text {Ink4a- }-}$, p $19^{\text {Arf }-/-}$ multipotent progenitors. Nature 453: 228-232.

Alvarado, Y., Apostolidou, E., Swords, R., and Giles, F.J. 2007. Emerging therapeutic options for Philadelphia-positive acute lymphocytic leukemia. Expert Opin. Emerg. Drugs 12: $165-179$.

Arico, M., Valsecchi, M.G., Camitta, B., Schrappe, M., Chessells, J., Baruchel, A., Gaynon, P., Silverman, L., JankaSchaub, G., Kamps, W., Pui, C.-H., and Masera, G. 2000. Outcome of treatment in children with Philadelphia chromosome-positive acute lymphoblastic leukemia. N. Engl. J. Med. 342: 998-1006.

Armstrong, S.A. and Look, A.T. 2005. Molecular genetics of acute lymphoblastic leukemia. J. Clin. Oncol. 23: 6306-6315.

Calabretta, B. and Perrotti, D. 2004. The biology of CML blast crisis. Blood 103: 4010-4022.

Castor, A., Nilsson, L., Astrand-Grundstrom, I., Buitenhuis, M., Ramirez, C., Anderson, K., Strombeck, B., Garwicz, S., Bekassy, A.N., Schmiegelow, K., et al. 2005. Distinct patterns of hematopoietic stem cell involvement in acute lymphoblastic leukemia. Nat. Med. 11: 630-637.

Chan, L.C., Karhi, K.K., Rayter, S.I., Heisterkamp, N., Eridani, S., Powles, R., Lawler, S.D., Groffen, J., Foulkes, J.G., Greaves, M.F., and Wiedemann, L.M. 1987. A novel abl protein expressed in Philadelphia chromosome positive acute lymphoblastic leukemia. Nature 325: 635-637.

Clark, S.S., McLaughlin, J., Crist, W.M., Champlin, R., and Witte, O.N. 1987. Unique forms of the $a b l$ tyrosine kinase distinguish $\mathrm{Ph}^{1}$-positive CML from $\mathrm{Ph}^{1}$-positive ALL. Science 235: $85-88$.

Clarke, M.F., Dick, J.E., Dirks, P.B., Eaves, C.J., Jamieson, C.H.M., Jones, D.L., Visvader, J., Weissman, I.L., and Wahl, G.M. 2006. Cancer stem cells-Perspectives on current status and future directions: AACR workshop on cancer stem cells. Cancer Res. 66: 9339-9344.

de Labarthe, A., Rousselot, P., Huguet-Rigal, F., Delabesse, E., Witz, F., Maury, S., Rea, D., Cayuela, J.-M., Vekemans, M.C., Reman, O., et al. 2007. Imatinib combined with induction or consolidation chemotherapy in patients with de novo Philadelphia chromosome-positive acute lymphoblastic leukemia: Results of the GRAAPH-2003 study. Blood 109: 1408-1413.

Druker, B.J., Sawyers, C.L., Kantarjian, H., Resta, D.J., Reese, S.F., Ford, J.M., Capdeville, R., and Talpaz, M. 2001. Activity of a specific inhibitor of the BCR-ABL tyrosine kinase in the blast crisis of chronic myeloid leukemia and acute lymphoblastic leukemia with the Philadelphia chromosome. N. Engl. J. Med. 344: 1038-1042.

Druker, B.J., Guilhot, F., O’Brien, S.G., Gathmann, I., Kantarjian, H., Gattermann, N., Deininger, M.W., Silver, R.T., Goldman, J.M., Stone, R.M., et al. 2006. Five-year follow-up of patients receiving imatinib for chronic myeloid leukemia. N. Engl. J. Med. 355: 2408-2417.

Gleissner, B., Gokbuget, N., Bartram, C.R., Janssen, B., Rieder, H., Janssen, J.W., Fonatsch, C., Heyll, A., Voliotis, D., Beck, J., et al. 2002. Leading prognostic relevance of the BCR-ABL translocation in adult B-lineage lymphoblastic leukemia: A prospective study of the German Multicenter Trial Group and confirmed polymerase chain reaction analysis. Blood 99: 1536-1543.

Groffen, J., Stephenson, J.R., Heisterkamp, N., de Klein, A., Bartram, C.R., and Grosveld, G. 1984. Philadelphia chromosomal breakpoints are clustered within a limited region, $b c r$, on chromosome 22. Cell 36: 93-99. 
Hochhaus, A., Kantarjian, H.M., Baccarani, M., Lipton, J.H., Apperley, J.F., Druker, B.J., Facon, T., Goldberg, S.L., Cervantes, F., Niederwieser, D., et al. 2007. Dasatinib induces notable hematologic and cytogenetic responses in chronicphase chronic myeloid leukemia after failure of imatinib therapy. Blood 109: 2303-2309.

Iwama, A., Oguro, H., Negishi, M., Kato, Y., Morita, Y., Tsukui, H., Ema, H., Kamijo, T., Katoh-Fukui, Y., Koseki, H., van Lohuizen, M., and Nakauchi, H. 2004. Enhanced self-renewal of hematopoietic stem cells mediated by the polycomb gene product Bmi-1. Immunity 21: 843-851.

Jacobs, J.J.L., Kieboom, K., Marino, S., DePinho, R.A., and van Lohuizen, M. 1999. The oncogene and Polycomb-group gene bmi-1 regulates cell proliferation and senescence through the ink4a locus. Nature 397: 164-168.

Jamieson, C.H., Ailles, L.E., Dylla, S.J., Muijtjens, M., Jones, C., Zehnder, J.L., Gotlib, J., Li, K., Manz, M.G., Keating, A., Sawyers, C.L., and Weissman, I.L. 2004. Granulocytemacrophage progenitors as candidate leukemic stem cells in blast crisis CML. N. Engl. J. Med. 351: 657-667.

Kantarjian, H., Giles, F., Wunderle, L., Bhalla, K., O'Brien, S., Wassmann, B., Tanaka, C., Manley, P., Rae, P., Mietlowski, W., et al. 2006. Nilotinib in imatinib-resistant CML and Philadelphia chromosome-positive ALL. N. Engl. J. Med. 354: 2542-2551.

Kohno, T. and Yokota, J. 2006. Molecular processes of chromosome 9p21 deletions causing inactivation of the p16 tumor suppressor gene in human cancer: Deduction from structural analysis of breakpoints for deletions. DNA Repair 5: 1273-1281

Krimpenfort, P., Ijpenberg, A., Song, J.Y., van der Valk, M., Nawijn, M., Zevenhoven, J., and Berns, A. 2007. p1 $5^{\text {Ink4b }}$ is a critical tumour suppressor in the absence of $16^{\text {lnk4a }}$. Nature 448: 943-946.

Lessard, J. and Sauvageau, G. 2003. Bmi-1 determines the proliferative capacity of normal and leukaemic stem cells. Nature 423: $255-260$.

Mullighan, C.G., Williams, R.T., Downing, J.R., and Sherr, C.J. 2008a. Failure of CDKN2A/B (INK4A/B-ARF)-mediated tumor suppression and resistance to targeted therapy in acute lymphoblastic leukemia induced by BCR-ABL. Genes Dev 22: 1411-1415.
Mullighan, C.G., Miller, C.B., Radtke, I,, Phillips, L.A., Dalton, J., Ma, J., White, D., Hughes, T.P., Le Beau, M.M., Pui, C.H., et al. 2008b. BCR-ABL1 lymphoblastic leukemia is characterized by the deletion of Ikaros. Nature 453: 110-114.

Nowell, P.C. and Hungerford, D.A. 1960. Chromosome studies on normal and leukemic human leukocytes. J. Natl. Cancer Inst. 25: 85-109.

O'Hare, T., Eide, C.A., and Deininger, M.W. 2007. Bcr-Abl kinase domain mutations, drug resistance, and the road to a cure for chronic myeloid leukemia. Blood 110: 2242-2249.

Park, I.-K., Qian, D., Kiel, M., Becker, M.W., Pihalja, M., Weissman, I.L., Morrison, S.J., and Clarke, M.F. 2003. Bmi1 is required for maintenance of adult self-renewing haematopoietic stem cells. Nature 423: 302-305.

Rowley, J.D. 1973. A new consistent chromosomal abnormality in chronic myelogenous leukemia. Nature 243: 290-293.

Shah, N.P., Nicoll, J.M., Nagar, B., Gorre, M.E., Paquette, R.L., Kuriyan, J., and Sawyers, C.L. 2002. Multiple BCR-ABL kinase domain mutations confer polyclonal resistance to the tyrosine kinase inhibitor imatinib (STI571) in chronic phase and blast crisis chronic myeloid leukemia. Cancer Cell 2: 117-125.

Shah, N.P., Tran, C., Lee, F.Y., Chen, P., Norris, D., and Sawyers, C.L. 2004. Overriding imatinib resistance with a novel ABL kinase inhibitor. Science 305: 399-401.

Talpaz, M., Shah, N.P., Kantarjian, H., Donato, N., Nicoll, J., Paquette, R., Cortes, J., O'Brien, S., Nicaise, C., Bleickardt, E., et al. 2006. Dasatinib in imatinib-resistant Philadelphia chromosome-positive leukemias. N. Engl. J. Med. 354: 25312541.

Williams, R.T., Roussel, M.F., and Sherr, C.J. 2006. Arf gene loss enhances oncogenicity and limits imatinib response in mouse models of Bcr-Abl-induced acute lymphoblastic leukemia. Proc. Natl. Acad. Sci. 103: 6688-6693.

Williams, R.T., den Besten, W., and Sherr, C.J. 2007. Cytokinedependent imatinib resistance in mouse BCR-ABL ${ }^{+}, A r f$-null lymphoblastic leukemia. Genes Dev. 21: 2283-2287.

Wong, S. and Witte, O.N. 2004. The BCR-ABL story: Bench to bedside and back. Annu. Rev. Immunol. 22: 247-306.

Zhao, C., Blum, J., Chen, A., Kwon, H.Y., Jung, S.H., Cook, J.M., Lagoo, A., and Reya, T. 2007. Loss of $\beta$-catenin impairs the renewal of normal and CML stem cells in vivo. Cancer Cell 12: 528-541. 


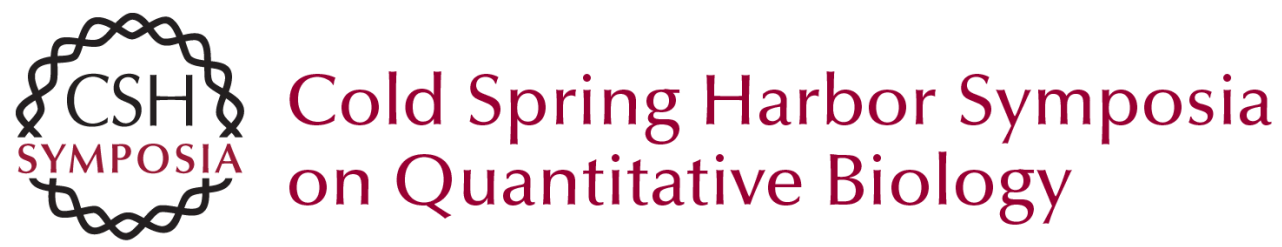

\section{The INK4-ARF (CDKN2A/B) Locus in Hematopoiesis and BCR-ABL- induced Leukemias}

R.T. Williams and C.J. Sherr

Cold Spring Harb Symp Quant Biol 2008 73: 461-467 originally published online November 21, 2008 Access the most recent version at doi:10.1101/sqb.2008.73.039

References This article cites 35 articles, 12 of which can be accessed free at: http://symposium.cshlp.org/content/73/461.full.html\#ref-list-1

\section{License}

Email Alerting Service top right corner of the article or click here. 